\title{
Assessing Biodegradability of PVA/Starch Based Composite Films Reinforced With Long Chain Fatty Acid Grafted Barley Husk
}

\section{Aanchal Mittal}

Dr. B. R. Ambedkar National Institute of Technology

\section{Sangeeta Garg ( $\nabla$ gargs@nitj.ac.in )}

Dr. B. R. Ambedkar National Institute of Technology

\section{Shailendra Bajpai}

Dr. B. R. Ambedkar National Institute of Technology

\section{Research Article}

Keywords: composite film, biodegradability, soil burial degradation, activated sludge, aerobic environment

Posted Date: September 7th, 2021

DOI: https://doi.org/10.21203/rs.3.rs-746515/v1

License: (c) (i) This work is licensed under a Creative Commons Attribution 4.0 International License.

Read Full License 
Assessing biodegradability of PVA/starch based composite films reinforced with long chain fatty acid grafted barley husk

\author{
Aanchal Mittal $^{1}$, Sangeeta Garg ${ }^{1 *}$, Shailendra Bajpai ${ }^{1}$ \\ ${ }^{1}$ Department of Chemical Engineering, Dr. B. R. Ambedkar National Institute of Technology, \\ Jalandhar, India. \\ *Email: [gargs@nitj.ac.in]
}

\begin{abstract}
The main objective of this study is the preparation of poly (vinyl alcohol) PVA/starch based composite films reinforced with barley husk and grafted barley husk (prepared using lauric acid, palmitic acid and arachidic acid) for packaging applications and assessment of their biodegradability. The biodegradability test of the films was performed by measuring weight loss of the films after degradation in soil under natural environmental conditions and by measuring evolved carbon dioxide $\left(\mathrm{CO}_{2}\right)$ during degradation under aqueous aerobic environment containing activated sludge. Physico-chemical variation in the films after degradation were observed using scanning electron microscopy (SEM) and Fourier transform infrared spectroscopy (FT-IR). The composite films containing barley husk showed highest degradation in soil (70 \% after 180 days) as well as in aqueous aerobic medium (58.83\% after 30 days). The results of scanning electron microscopy showed the formation of cracks and holes over the surface of the composite films after degradation. The degradation of the films occurred inside the composite films, not only on their surface. The incorporation of starch and barley husk in PVA matrix enhanced the degradation rate of films.
\end{abstract}

Keywords composite film, biodegradability, soil burial degradation, activated sludge, aerobic environment

\title{
1. Introduction
}

There has been introduction of new regulations considering the processing and manufacturing of the plastic products using modified natural polymers or synthetic raw materials in the European Union (Directive EU 2019/904) (Borowski et al. 2020). The marketing of single use plastic products will be prohibited from 2021 onwards. There is also possibility that the composites made from non-degradable and synthetic polymers may be replaced with biocomposites containing natural fillers in the near future (Ibrahim et al. 2020). Therefore, the research is more focused towards replacement of non-degradable synthetic plastic with environment friendly and biodegradable materials (Liu et al. 2019). The interest towards utilization of environmentally degradable biopolymers such as starch, cellulosic materials, chitosan, poly vinyl alcohol for packaging applications have been increasing because of their complete and faster biodegradation compared to synthetic polymers (More et al. 2017; Garg et al. 2019; Priya et al. 2013, Popescu et al. 2010; Jain et al. 2018; Dolez et al. 2017). Poly vinyl alcohol (PVA) is one of the most widely used synthetic polymer in packaging industries as it is degradable under natural environmental conditions (Kaur et al. 2018). Incorporation of various cellulosic fillers with polymer matrix has been preferred to improve the biodegradability of the composite films (Elhussieny et al. 2020; Priya et al. 2013). 
The biodegradation of complex biomaterials results into small and environmentally acceptable products such as $\mathrm{CO}_{2}$, water and biomass by naturally available microorganisms (bacteria and fungi) and other biological activity under natural environmental conditions. However, now-a-days there have been an increased demand for biodegradability and more reliable biodegradation data of the packaging films due to raised concerns about the environment quality. Therefore, many researchers have made efforts towards establishment of different methods for biodegradation of packaging films by observing change in physical and chemical properties of films (Garg and Jana, 2011; Mittal et al. 2020b; Hoffman et al. 2003; Tripathy et al. 2018; Kaith et al. 2009; Negim et al. 2014; Abdullah et al. 2017; Castro-Aguirre et al. 2018, Borowski et al. 2020). Soil burial degradation method is the most common method based on the direct measurement of weight loss of the film after biodegradation under natural environmental condition (Mittal et al. 2016, Garg and Jana, 2011). Another indirect method for evaluation of biodegradability is based on the measurement of evolved $\mathrm{CO}_{2}$ during the biodegradation of film in aqueous aerobic medium (Strotmannet al. 2004; Hoffamann et al. 2003). The biodegradability of the PVA/corn starch based composite films reinforced with orange fiber was measured using soil burial degradation method and by measuring evolved $\mathrm{CO}_{2}$ during degradation (Imam et al. 2005). The addition of orange fiber and starch in the blend also stimulated the degradation of PVA as starch and lignocellulosic fiber are easily degraded by microbes. In literature, neither PVA/starch based composite films reinforced with BH and grafted BH (prepared using lauric acid, palmitic acid and arachidic acid) were synthesized nor the effect of their reinforcement on the biodegradability of composite film by measuring evolved $\mathrm{CO}_{2}$ during degradation of films was studied.

Therefore, present work deals with the biodegradation study of the PVA/starch based composite films containing $\mathrm{BH}$ and grafted $\mathrm{BH}$ (prepared using lauric acid, palmitic acid and arachidic acid) by soil burial degradation test in natural environmental conditions and by $\mathrm{CO}_{2}$ evolution method in aqueous medium. The composite films were characterized by using scanning electron microscopy (SEM) and Fourier transform infrared spectroscopy (FT-IR) before and after biodegradation test.

\section{Materials and Methods}

\subsection{Materials}

Barley was obtained from the local market of Jalandhar, India. Lauric acid (purity, 99.0\%) was procured from Himedia Laboratories Pvt. Ltd. (Mumbai, India). Palmitic acid (purity, 99.5\%) was received from Sisco Research Laboratories Pvt. Ltd. (Bombay, India). Arachidic acid (purity, > 99\%) was obtained from SigmaAldrich (Mumbai, India). Dimethyl sulphoxide (DMSO), potassium per sulpahte (KPS) and ferrous ammonium sulphate (FAS) were provided by Loba Chemie Pvt. Ltd. (Mumbai, India). Polyvinyl alcohol with average molecular wt. 14,000, glycerol, formic acid, urea and formaldehyde (37-40\% formalin solution) were purchased from s. d. fine Chemicals ltd. (Mumbai, India). Corn starch was received by Sukhjit Starch and Chemicals Ltd. (Phagwara, India). All the chemicals were of analytical grade and used without any further purification.

\subsection{Methods}

\subsubsection{Preparation of films}


PVA/St blend films were prepared by casting method as reported in our earlier studies (Mittal et al. 2016; Mittal et al. 2020a, b). Starch (5g) was gelatinized in hot water and mixed with PVA solution. The mixture of PVA and starch was continuously stirred for $45 \mathrm{~min}$ at $50^{\circ} \mathrm{C}$ using mechanical stirrer ( $400 \mathrm{rpm}$ ) to form a homogeneous gel solution. Plasticizing agent (glycerol) was added to the above mixture. The PVA/St suspension was poured onto the glass petri dish (dia. $14 \mathrm{~cm})$, dried in hot air oven $\left(24 \mathrm{~h}\right.$ at $\left.45^{\circ} \mathrm{C}\right)$ and the dried film was peeled off from the dish. Cross linked films were prepared using urea formaldehyde as crosslinking agent in PVA/St matrix (Mittal et al. 2016). Urea formaldehyde prepolymer was prepared by refluxing of formalin solution with urea (molar ratio 1:1.5) for 15 min. The crosslinker was added slowly in PVA/St suspension in acidic condition (pH 3.0) and the mixture was continuously stirred. The crosslinked films were prepared by solvent casting method with urea/starch ratio $0.5(\mathrm{w} / \mathrm{w})$.

The composite films were prepared by reinforcing $\mathrm{BH}$ and fatty acid grafted $\mathrm{BH}$ within crosslinked PVA/St matrix. The preparation of grafted $\mathrm{BH}(\mathrm{LBH} 45, \mathrm{PBH} 41.5$ and $\mathrm{ABH} 48.2)$ using lauric acid, palmitic acid and arachidic acid has been reported in our previous studies (Mittal et al. 2019a and Mittal et al. 2019b). BH and grafted BH (0.2- 2\% (w/w)) were mixed with cross linked PVA/St suspension using a mechanical stirrer. The composite mixture was poured onto petri dishes and dried at $45^{\circ} \mathrm{C}$. The dried composite films were peeled off after 24h. Composition of various films has been shown in Table 1.

\subsubsection{Characterization}

IR spectra of the films before and after degradation was recorded in order to study the chemical changes occurred in the films after degradation. The film samples were equilibrated at $50^{\circ} \mathrm{C}$ and analyzed by FT-IR instrument (Perkin Elmer, Model RX - 1) at a resolution of $4 \mathrm{~cm}^{-1}$ within range $4000-400 \mathrm{~cm}^{-1}$ using $\mathrm{KBr}$ pellets obtained from Sigma Aldrich. The surface morphology of the films before and after degradation was studied using a scanning electron microscope (JEOL JSM-6100, JEOL, Tokyo, Japan) at a magnification up to $2000 \mathrm{X}$. To avoid the charging under electron beam, the film samples were coated with gold in argon.

\subsubsection{Biodegradation study}

\subsubsection{Soil burial degradation test}

The soil burial degradation test of the films $(3 \mathrm{~cm} \times 10 \mathrm{~cm})$ was performed by burying all the samples in soil at $10 \mathrm{~cm}$ depth under natural environmental conditions. The moisture and microbial concentration was maintained by sprinkling sewage water over the soil. The samples were taken out after every 15 days and washed with distilled water. The samples were dried in hot air oven and the weight loss (\%) was calculated as (Mittal et al. 2016).

$$
\text { Weight loss }(\%)=\frac{W_{d}-W_{i}}{W_{i}} \times 100
$$

Where $\mathrm{W}_{\mathrm{i}}$ is initial weight of the sample and $\mathrm{W}_{\mathrm{d}}$ is final weight of the sample after degradation.

\subsubsection{Evaluation of biodegradability of films using $\mathrm{CO}_{2}$ evolution test}


The test was done by determining the evolved carbon dioxide during degradation of films by ISO 9439:2000 procedure. The produced $\mathrm{CO}_{2}$ during the degradation of sample was dissolved in the solution of hydroxide and the subsequent amount of produced $\mathrm{CO}_{2}$ was determined by titration. The percentage of degradation of the sample was further calculated by knowing the amount of produced $\mathrm{CO}_{2}$ during the degradation test.

The experimental setup used is shown in Fig 1. The set up consists of three parts: common cleaning part, two reactors and absorbers. The cleaning part consists of two gas washing vessels containing $500 \mathrm{~mL}$ of $\mathrm{NaOH}$ solution $(10 \mathrm{~mol} / \mathrm{L})$ and $100 \mathrm{~mL}$ of $\mathrm{Ba}(\mathrm{OH})_{2}$ solution $(0.0125 \mathrm{~mol} / \mathrm{L})$., respectively. $\mathrm{CO}_{2}$ free air from cleaning part was then supplied to two reactors (Erlenmeyer flask) which were continuously stirred. First reactor contains inorganic medium, inoculum and test sample while second reactor contained inorganic medium and inoculum. The sample was the nominal sole source of organic carbon and energy in the cultivating aqueous medium. $\mathrm{CO}_{2}$ evolved during degradation of sample was passed through third part (absorbers). Third part consists of three absorbers: one safety absorber and two absorbers containing $30 \mathrm{~mL}$ of $\mathrm{Ba}(\mathrm{OH})_{2}$ solution $(0.0125 \mathrm{~mol} / \mathrm{L})$. The flow rate of air was maintained to $50-100 \mathrm{~mL} / \mathrm{min}$ in the whole apparatus. The degradation test was performed in dark and the total volume of test mixture in individual reactor was maintained to $2500 \mathrm{~mL}$. Inorganic test medium was prepared in accordance to ISO 9439:2000 procedure. Inoculation was done using activated adapted sludge in a dose of approx. $0.5 \mathrm{~g} / \mathrm{L}$. The concentration of test sample in the medium was maintained to $40 \mathrm{mg} / \mathrm{L}$. The abiotic test was also performed with mercuric chloride $(10 \mathrm{~g} / \mathrm{L})$ by similar method. Aniline was used a reference compound for the degradation test with same concentration as test sample.

\section{Investigating $\mathrm{CO}_{2}$ production}

Absorbers containing $\mathrm{Ba}(\mathrm{OH})_{2}$ were exchanged daily with freshly prepared $\mathrm{Ba}(\mathrm{OH})_{2}$ solution. Amount of produced $\mathrm{CO}_{2}$ was determined by titrating the replaced $\mathrm{Ba}(\mathrm{OH})_{2}$ solution with $\mathrm{HCl}$ solution $(0.05 \mathrm{~mol} / \mathrm{L})$ using phenolphthalein as an indicator to determine the end point.

Produced $\mathrm{CO}_{2}$ reacted with $\mathrm{Ba}(\mathrm{OH})_{2}$ to form precipitation of $\mathrm{BaCO}_{3}$ as shown in the following reactions.

$$
\begin{aligned}
& \mathrm{CO}_{2}+\mathrm{Ba}(\mathrm{OH})_{2} \rightarrow \mathrm{BaCO}_{3}+\mathrm{H}_{2} \mathrm{O} \\
& \mathrm{Ba}(\mathrm{OH})_{2}+2 \mathrm{HCl} \rightarrow \mathrm{BaCl}_{2}+2 \mathrm{H}_{2} \mathrm{O}
\end{aligned}
$$

The mass of $\mathrm{CO}_{2}$ dissolved in the absorber vessel was calculated using Eq. 1.

$m_{T}=\left\{\frac{2 c_{B a} \cdot V_{B 0}}{c_{H C l}}-v_{A} \frac{V_{B T}}{V_{B Z}}\right\} \cdot c_{H C l} \times 22$

Where $m_{T}$ is the mass of $\mathrm{CO}_{2}$ trapped in the absorber of vessel $(\mathrm{mg}), c_{\mathrm{HCl}}$ is the concentration of the $\mathrm{HCl}$ solution $(\mathrm{mol} / \mathrm{L}), c_{B a}$ is the concentration of the $\mathrm{Ba}(\mathrm{OH})_{2}$ solution $(\mathrm{mol} / \mathrm{L}), V_{B 0}$ is the volume of the $\mathrm{Ba}(\mathrm{OH})_{2}$ solution $(\mathrm{mL})$ at the beginning of the test, $V_{B T}$ is the volume of the $\mathrm{Ba}(\mathrm{OH})_{2}$ solution $(\mathrm{mL})$ at time $\mathrm{t} ; V_{B Z}$ is the volume of the aliquots of the $\mathrm{Ba}(\mathrm{OH})_{2}$ solution $(\mathrm{mL})$ used for titration; $V_{A}$ is the volume of the $\mathrm{HCl}$ solution $(\mathrm{mL})$ used for titration of the $\mathrm{Ba}(\mathrm{OH})_{2}$ solution.

When volume of the $\mathrm{Ba}(\mathrm{OH})_{2}$ solution before and after absorption is exactly $100 \mathrm{ml}$ and the complete solution is used

$\left(\mathrm{V}_{\mathrm{BT}}=\mathrm{V}_{\mathrm{B} 0}=\mathrm{V}_{\mathrm{BZ}}\right)$ 
$\mathrm{ThCO}_{2}=\rho_{\mathrm{c}} \times \mathrm{V}_{\mathrm{L}} \times 44 / 12$

136

138

$\mathrm{D}=\frac{\sum \mathrm{m}_{\mathrm{Tt}}-\sum \mathrm{m}_{\mathrm{Bt}}}{\mathrm{ThCO}_{2}} \times 100$

Where $\sum m_{T t}$ is the mass of $\mathrm{CO}_{2}$ released $(\mathrm{mg})$ between the start of the test and time $\mathrm{t}$ and $\sum m_{B t}$ is the amount of $\mathrm{CO}_{2}$ released $(\mathrm{mg})$ in blank control between the start of the test and time $\mathrm{t}$.

\section{3. Results and discussion}

\section{$142 \quad 3.1$ Soil burial degradation}

Biodegradability of the films is one of the major properties which potentially control their applications. The degradation test of the blend films (PVA, PVA/St and PVA-0.5C St) and composite films containing BH, LBH 45, $\mathrm{PBH} 41.5$ and $\mathrm{ABH} 48.2$ was performed after burying the films for 180 days in soil under natural environmental conditions. Weight loss (\%) of films was measured with time and results are shown in Fig. 2. It was observed that after burying the films in the soil, the size of the films reduced and the surface of films became hard and fragile. Results indicated that the weight loss (\%) of the films was rapid upto 120 days of burial in soil and thereafter it was constant. PVA film showed $1.86 \%$ weight loss after 45 days and it increased to $16.4 \%$ after 180 days. The degradation rate of film (PVA/St) increased after blending 50\% starch in PVA matrix and showed 59\% weight loss after 180 days. However, weight loss of the film (PVA-0.5C St) decreased to $44.6 \%$ after 180 days of incubation in soil.

It was observed that biodegradability of composite films improved after incorporation of $\mathrm{BH}(0.2-2 \%)$ in crosslinked PVA/St matrix (Fig. 2a). After reinforcement of $0.2 \% \mathrm{BH}$ in the matrix, weight loss of the film (PVA-0.5C St-0.2BH) was $26.6 \%$ after 45 days of soil burial and increased to $54.3 \%$ after 180 days. Composite film (PVA-0.5CSt-1BH) containing 1\% BH showed approximately $42.2 \%$ weight loss after 45 days of degradation test which increased to $70 \%$ after 180 days. \% Weight loss of the film (PVA-0.5C St-2BH) increased to $73.4 \%$ after 180 days with increase in $\mathrm{BH}$ content to $2 \%$ in the matrix. The degradation rate of $\mathrm{BH}$ composite film was higher due to their ability to absorb higher amount of moisture (Imam et al. 2005). The water absorbed by the films caused the swelling of the films and allowed the growth of microbes on their surface by utilizing the nutrients present in the films leading to their disruption and weight loss (Ooi et al. 2012). Ibrahim et al. (2020) also observed increase in biodegradability of starch based films after reinforcement of corn husk fiber. The starch based film showed $47.13 \%$ weight loss after 18 days whereas, the starch based composite film containing $8 \%$ corn husk fiber resulted in $73.22 \%$ weight loss after 18 days due to increase in number of 
The results of soil burial degradation test of grafted BH composite films are shown in Fig. 2. It was observed that incorporation of grafted $\mathrm{BH}(\mathrm{LBH} 45, \mathrm{PBH} 41.5$ and $\mathrm{ABH} 48.2)$ into crosslinked PVA/St matrix resulted in increase in \% weight loss of the films. Composite films (PVA-0.5C St -1LBH 45, PVA-0.5C St-1PBH 41.5 and PVA-0.5C St-1ABH 48.2) showed 68.1\%, 65.1\% and 64.2\% weight losses, respectively after 180 days of soil burial degradation test. Results indicated that reinforcement of grafted $\mathrm{BH}$ into cross-linked PVA/St matrix resulted in lower degradation of the films as compared to $\mathrm{BH}$ composite films due to improved water resistant properties of composite films containing grafted $\mathrm{BH}$ and lower affinity towards microbial attack.

\section{2 $\mathrm{CO}_{2}$ evolution test}

Biodegradation test of the films (PVA, PVA-0.5C St-1BH, PVA-0.5C St-1LBH 45, PVA-0.5C St-1PBH 41.5, PVA-0.5C St-1 ABH 48.2) was also performed in an aqueous medium containing activated sludge from the waste water treatment plant and biodegradability was measured by measuring the evolved $\mathrm{CO}_{2}$ during the degradation process. Biodegradability of the samples was evaluated on the basis of evolved $\mathrm{CO}_{2}$ using ISO 9439:2000 procedure. The results of $\mathrm{CO}_{2}$ production during biodegradation of the films and reference compound (aniline) as a function of time (days) are shown in Fig. 3. The abiotic test was performed under the same conditions to check the abiotic degradation of the test sample (film). The results showed that abiotic test resulted in very low $\mathrm{CO}_{2}$ production (approx. $5 \%$ of total production). The blank tests containing inoculum and inorganic medium were run in parallel with all the test samples. The $\mathrm{CO}_{2}$ production in all the blank tests was low and contributed to approximately $33 \%$ of total $\mathrm{CO}_{2}$ produced in the degradation test. Aniline was taken as reference compound and showed highest $\mathrm{CO}_{2}$ production $(331.7 \mathrm{mg})$ as it is highly degradable in the given test conditions. The $\mathrm{CO}_{2}$ production during degradation of PVA film was $161.37 \mathrm{mg}$ after 30 days of test. However, composite film (PVA-0.5C St-1BH) containing $1 \% \mathrm{BH}$ showed $315 \mathrm{mg}$ of $\mathrm{CO}_{2}$ production after 30 days and was much higher than blank test.

There was not much significant variation in the amount of $\mathrm{CO}_{2}$ produced during degradation of composite films containing BH and grafted BH. Composite film (PVA-0.5C St-1LBH 45, PVA-0.5C St-1PBH 41.5 and PVA$0.5 \mathrm{C}$ St-1ABH 48.2) showed $300.85 \mathrm{mg}, 293.48 \mathrm{mg}$ and $290.73 \mathrm{mg}$ of $\mathrm{CO}_{2}$ production after 30 days, respectively. The incorporation of starch and $\mathrm{BH}$ into the PVA matrix stimulated the degradation of PVA. Imam et al. (2005) also reported that in the PVA-starch matrix first starch degraded quickly. When the starch concentration is below than percolation threshold, the microbes switched to another easily available, accessible and abundant carbon source such as PVA.

The degradation rate of various films and reference compound (aniline) was calculated (Eq. 3) based on the $\mathrm{CO}_{2}$ production and the results are shown in Fig. 4. The biodegradation curves of all the films showed four phases: lag phase of 3 days; a short exponential phase of 3-4 days, linear phase and plateau phase (reached approximately after 20 days of biodegradation of the films) (Lefaux et al. 2004). Results emphasized that degradation of aniline (reference compound) was $65.2 \%$ after 30 days. PVA film showed degradation of $9.36 \%$ after 20 days of the degradation test and increased to $12.7 \%$ after 30 days.

The degradation of BH composite film (PVA-0.5C St-1BH) was $58.83 \%$ after 30 days and was higher than PVA film due to addition of biodegradable starch and BH within PVA matrix. Composite films (PVA-0.5C St-1LBH 45, PVA-0.5C St-1PBH 41.5 and PVA-0.5C St-1ABH 48.2) containing LBH 45, PBH 41.5 and ABH 48.2 
showed degradation of $54.66 \%, 52.33 \%$ and $51.43 \%$, respectively after 30 days of the degradation test. Composite films containing grafted BH showed higher degradation rate as compared to PVA film.

\subsection{Scanning electron microscopy}

The change in the surface morphology of PVA, PVA/St and crosslinked film (PVA-0.5C St) was studied after 180 days of soil burial degradation test and the results are shown in Fig. 5. It was observed that the surface of the films was detoriated and showed surface irregularities after degradation. The large longitudinal cracks, holes and cavities were formed on the surface of the films indicated that microorganisms have attacked the surface of the films when buried in soil under natural environmental conditions. The surface micrograph of PVA/St film was rough and eroded compared to PVA film due to degradation of starch within PVA/St matrix Jayasekara et al. (2003) also studied the biodegradation behavior of PVA/starch films by composting method and reported the increased roughness on the surface of PVA/starch blend film after 45 days of degradation test due to rapid degradation of starch.

Results showed that incorporation of $\mathrm{BH}$ and grafted $\mathrm{BH}$ into the crosslinked PVA/St matrix increased the degradation of the films. The surface morphology of composite films containing BH and grafted BH (LBH 45, PBH 41.5 and ABH 48.2) before and after degradation test is shown in Fig. 6. SEM images of BH composite film (PVA-0.5C St-1BH) showed the formation of big holes and pits on the surface of the films after 180 days of degradation. After burying of $\mathrm{BH}$ composite film into the soil, the microorganisms evidently attacked the starch and cellulosic material (BH) present in the film leading to degradation of other components also (Stelescu et al. 2017; Jayasekara et al. 2003). Before degradation, the surface of the composite films containing grafted $\mathrm{BH}$ was homogenous and smooth as compared to $\mathrm{BH}$ composite film due to improved adhesion between grafted $\mathrm{BH}$ and PVA/starch matrix leading to improved mechanical properties and barrier properties of the films (Mittal et al. 2016). After degradation, the surface of the composite films (PVA-0.5C St-1LBH 45, PVA-0.5C St-1PBH 41.5 and PVA-0.5C St-1 ABH 48.2) became heterogeneous and rough, while holes and cavities also appeared on the surface of the films (Kaith et al. 2009).

\subsection{FT-IR analysis}

After 180 days of degradation of the films in soil, fragments of the degraded samples were analyzed by FT-IR spectroscopy. Fig 7 showed the IR spectra of PVA film, PVA/St film, crosslinked film (PVA-0.5C St) and composite films (PVA-0.5C St-1BH, PVA-0.5C St-1LBH 45, PVA-0.5C St-1PBH 41.5 and PVA-0.5C St$1 \mathrm{ABH} 48.2$ ) before and after 180 days of degradation.

IR spectra of all degraded film samples showed the decrease in peak intensity corresponding to hydroxyl (3100$\left.3500 \mathrm{~cm}^{-1}\right)$ and methylene (2700-2900 $\mathrm{cm}^{-1}$ ) groups due to breakage of bonds during degradation. In addition, the reduction in peak intensity in the range $1100-1400 \mathrm{~cm}^{-1}$ (C-O stretching), $910-920 \mathrm{~cm}^{-1}\left(-\mathrm{CH}_{2}\right.$ rocking) and $820-830 \mathrm{~cm}^{-1}$ (C-C stretching) was observed in the spectra of degraded film samples (Kibédi-Szabó et al. 2012). 

produced during microbial growth on the film surface (Klemenčič et al. 2010).

\section{Conclusions}

243 Various composite films using PVA/starch as polymer matrix and barley husk or grafted barley husk as 244 reinforcing agent were synthesized. Biodegradability studies were performed using soil burial degradation method and carbon dioxide evolution method. The biodegradation rate of the films was measured by measuring weight loss after soil burial of the films and by evaluating evolved $\mathrm{CO}_{2}$ during degradation in aqueous aerobic medium. PVA film showed $16.4 \%$ degradation after 180 days under soil however, it increased to $54 \%$ after addition of 50\% starch into the PVA matrix. Further, crosslinking of PVA/starch matrix with urea formaldehyde resulted in decrease in degradation of the films by 5.6\%. After incorporation of $\mathrm{BH}(1 \%)$ in crosslinked PVA/starch matrix, $70 \%$ degradation of the composite films was achieved after 180 days of soil burial. Under aqueous aerobic environment, $\mathrm{BH}$ composite film (PVA-0.5C St-1BH) showed $314.93 \mathrm{mg}$ of $\mathrm{CO}_{2}$ production and $58.83 \%$ degradation after 30 days of test. However, composite films containing grafted BH showed slight decrease in the evolved $\mathrm{CO}_{2}$ and \% degradation than of $\mathrm{BH}$ composite film. The addition of starch and $\mathrm{BH}$ improved the degradation rate as they are completely biodegradable materials. The results of scanning electron microscopy showed the formation of cracks, holes and cavities over the surface of the composite films incorporated with $\mathrm{BH}$ after degradation. In conclusion, the addition of biomaterials such as starch and barley husk enhanced the degradation rate of the films. PVA/starch based composite film reinforced with barley husk and grafted barley husk may provide a potential and ecofriendly alternative to the conventional packaging films.

Declarations

Ethics approval and consent to participate: Not applicable

Availability of data and material: All data generated or analyzed during this study are included in this published article.

Competing interests: The authors declare that they have no competing interests.

Author Contributions: Aanchal Mittal has conducted all the research work, data organization, writing of original draft and editing. Dr. Sangeeta Garg is responsible for supervision, reviewing and editing. Dr. Shailendra Bajpai is responsible for supervision and editing. All authors read and approved the final manuscript. carrying out this work.

\section{References}


- Abdullah ZW, Dong Y, Davies IJ, Barbhuiya S (2017) PVA, PVA blends, and their nanocomposites for biodegradable packaging application. Polym Plast Technol Eng 56(12):1307-1344. https://doi.org/10.1080/03602559.2016.1275684

- Borowski G, Klepka T, Pawłowska M, Lavagnolo MC, Oniszczuk T, Wójtowicz A, Combrzyński M (2020). Effect of flax fibers addition on the mechanical properties and biodegradability of biocomposites based on thermoplastic starch. Arch Environ Prot 46(2):74-82. https://doi.org/10.24425/aep.2020.133477

- Castro-Aguirre E, Auras R, Selke S, Rubino M, Marsh T (2018) Impact of nanoclays on the biodegradation of poly (lactic acid) nanocomposites. Polymers 10(2):202. https://doi.org/10.3390/polym10020202

- Dolez PI, Arfaoui MA, Dubé M, David É (2017) Hydrophobic treatments for natural fibers based on metal oxide nanoparticles and fatty acids. Procedia Eng 200:81-88. https://doi:10.1016/j.proeng.2017.07.013.

- Garg S, Jana AK (2011) Effect of propylation of starch with different degrees of substitution on the properties and characteristics of starch-low density polyethylene blend films. J Appl Polym Sci 122(4):2197-2208. https://doi.org/10.1002/app.34279

- Garg S, Mittal A, Premi A (2019) Synthesis and Characterization of the Graft Copolymers of Starch for the Application in Packaging Films. In: Agnihotri AK, Reddy K, Bansal A (ed) Sustainable Engineering, Springer, Singapore, pp. 63-73. https://doi.org/10.1007/978-981-13-6717-5 7

- Ibrahim MIJ, Sapuan SM, Zainudin ES, Zuhri MYM (2020) Preparation and characterization of cornhusk/sugar palm fiber reinforced Cornstarch-based hybrid composites. J Mater Res Technol 9(1):200-211. https://doi.org/10.1016/j.jmrt.2019.10.045

- Kaith BS, Jindal R, Maiti M (2009) Graft copolymerization of methylmethacrylate onto acetylated Saccharum spontaneum L. Using FAS-KPS as a redox initiator and evaluation of physical, chemical, and thermal properties. Int J Polym Anal Charact 14(3):210-230. https://doi.org/10.1080/10236660802660791

- Kibédi-Szabó CZ, Stroescu M, Stoica-Guzun A, Jinga SI, Szilveszter S, Jipa I, Dobre T (2012) Biodegradation behavior of composite films with poly (vinyl alcohol) matrix. J Polym Environ 20(2): 422-430. https://doi.org/10.1007/s10924-011-0391-4

- Klemenčič D, Simončič B, Tomšič B, Orel B (2010) Biodegradation of silver functionalized cellulose fibres. Carb Polym 80(2):426-435. https://doi.org/10.1016/j.carbpol.2009.11.049

- Liu Y, Lv X, Bao J, Xie J, Tang X, Che J, Ma Y, Tong J (2019) Characterization of silane treated and untreated natural cellulosic fibre from corn stalk waste as potential reinforcement in polymer composites. Carb Polym 218:179-187. https://doi.org/10.1016/j.carbpol.2019.04.088

- Hoffmann J, Řezníčková I, Kozáková J, Růžička J, Alexy P, Bakoš D, Precnerová L (2003) Assessing biodegradability of plastics based on poly (vinyl alcohol) and protein wastes. Polym Degrad Stab 79(3):511-519. https://doi.org/10.1016/S0141-3910(02)00367-1 
- Huang Z, Qian L, Yin Q, Yu N, Liu T, Tian D (2018) Biodegradability studies of poly (butylene succinate) composites filled with sugarcane rind fiber. Polym Test 66:319-326. https://doi.org/10.1016/j.polymertesting.2018.02.003

- Imam SH, Cinelli P, Gordon SH, Chiellini E (2005) Characterization of biodegradable composite films prepared from blends of poly (vinyl alcohol), cornstarch, and lignocellulosic fiber.

- Jain J, Jain S, Sinha S (2018) Characterization and thermal kinetic analysis of pineapple leaf fibers and their reinforcement in epoxy, J Elastomers Plast 51(3):224-243. https://doi:10.1177/0095244318783024.

- Jayasekara R, Harding I, Bowater I, Christie GB, Lonergan GT (2003) Biodegradation by composting of surface modified starch and PVA blended films. J Polym Environ 11(2):49-56. https://doi.org/10.1023/A:1024219821633

- Kibédi-Szabó CZ, Stroescu M, Stoica-Guzun A, Jinga SI, Szilveszter S, Jipa I, Dobre T (2012) Biodegradation behavior of composite films with poly (vinyl alcohol) matrix. J Polym Environ 20(2):422-430.

- Lefaux S, Manceau A, Benguigui L, Campistron I, Laguerre A, Laulier M, Leignel V, Tremblin G (2004) Continuous automated measurement of carbon dioxide produced by microorganisms in aerobic conditions: application to proteic film biodegradation. C R Chim 7(2):97-101. https://doi.org/10.1016/j.crci.2003.10.008

- More AS, Sen C, Das M (2017) Development of Starch-Polyvinyl Alcohol (PVA) Biodegradable Film: Effect of Cross-Linking Agent and Antimicrobials on Film Characteristics. J Appl Packag Res 9(3):118. https://doi.org/10.1007/s10924-011-0391-4

- Mittal A, Garg S, Bajpai S (2020a) Fabrication and characteristics of poly (vinyl alcohol)-starchcellulosic material based biodegradable composite film for packaging application. Mater TodayProc 21:1577-1582. https://doi.org/10.1016/j.matpr.2019.11.210

- Mittal A, Garg S, Bajpai S (2020b) Thermal decomposition kinetics and properties of grafted barley husk reinforced PVA/starch composite films for packaging applications. Carb Polym 116225. https://doi.org/10.1016/j.carbpol.2020.116225

- Mittal A, Garg S, Bajpai S (2019a) Lauric acid-grafted barley (Hordeum vulagare L.) husk for application in biocomposite films: optimization method in synthesis and characterization. Iran Polym J 28(5):379-390. https://doi.org/10.1007/s13726-019-00707-5

- Mittal A, Garg S, Bajpai S (2019b) The influence of fatty acid chain length on the chemical, physical and morphological properties of the grafted barley husk for application in biocomposites. Polym Test 78:105937. https://doi.org/10.1016/j.polymertesting.2019.105937

- Mittal A, Garg S, Kohli D, Maiti M, Jana AK, Bajpai S (2016) Effect of cross linking of PVA/starch and reinforcement of modified barley husk on the properties of composite films. Carb polym 151:926938. https://doi.org/10.1016/j.carbpol.2016.06.037

- Negim ESM, Rakhmetullayeva RK, Yeligbayeva GZ, Urkimbaeva PI, Primzharova ST, Kaldybekov DB, Khatib JM, Mun GA, Craig W (2014) Improving biodegradability of polyvinyl alcohol/starch 
blend films for packaging applications. Int J Sci: Basic Appl 3(3):263.

https://doi.org/10.14419/ijbas.v3i3.2842

- Stevanovic T, Tibirna CM, Popescu MC, Sdrobis A, Vasile C, Totolin M (2010) Grafting of softwood kraft pulps fibers with fatty acids under cold plasma conditions, Int J Biol Macromol 48:326-335. https://doi:10.1016/j.ijbiomac.2010.12.011.

- Priya B, Gupta VK, Pathania D, Singha AS (2014) Synthesis, characterization and antibacterial activity of biodegradable starch/PVA composite films reinforced with cellulosic fibre. Carb polym 109:171179. https://doi.org/10.1016/j.carbpol.2014.03.044

- Stelescu MD, Airinei A, Manaila E, Craciun G, Fifere N, Varganici C (2017) Property correlations for composites based on ethylene propylene diene rubber reinforced with flax fibers. Polym Test 59:75-83. https://doi.org/10.1016/j.polymertesting.2017.01.017

- Strotmann U, Reuschenbach P, Schwarz H, Pagga U (2004) Development and evaluation of an online $\mathrm{CO} 2$ evolution test and a multicomponent biodegradation test system. Appl Environ Microbiol 70(8):4621-4628. https://doi.org/10.1128/AEM.70.8.4621-4628.2004

- Tripathy S, Pradhan C, Parida C (2018) Study of biodegradation of luffa cylindrica/poly (lactic) acid composites. Int J Curr Rs Rev 10(1):1-5. https://doi.org/10.7324/IJCRR.2018.1021 


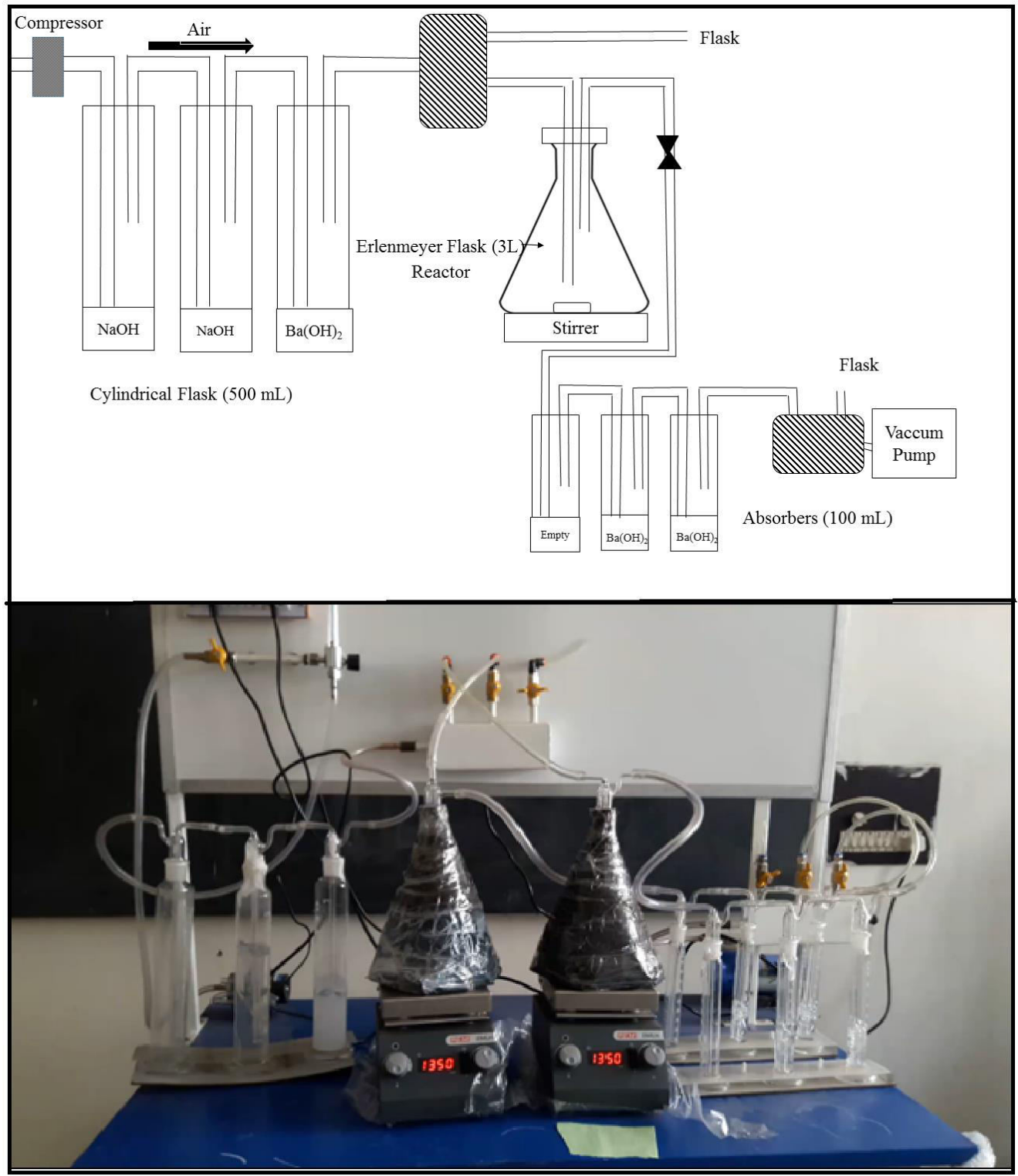

375 Fig. 1 Experimental setup for measuring evolved $\mathrm{CO}_{2}$ during degradation of composite films in aqueous aerobic medium ( 1 of 2 reactors is shown). 


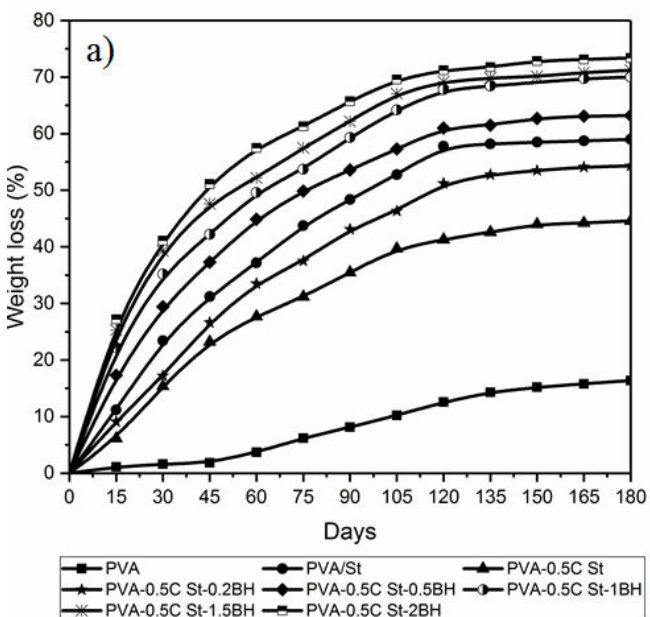

$\rightarrow$ PVA-0.5C St-0.2BH $\rightarrow$ PVA-0.5C St-0.5BH $\rightarrow$ PVA- $0.5 \mathrm{C} \mathrm{St}-1 \mathrm{BH}$ -PVA-0.5C St-1.5BH $\rightarrow$ PVA-0.5C St-2BH
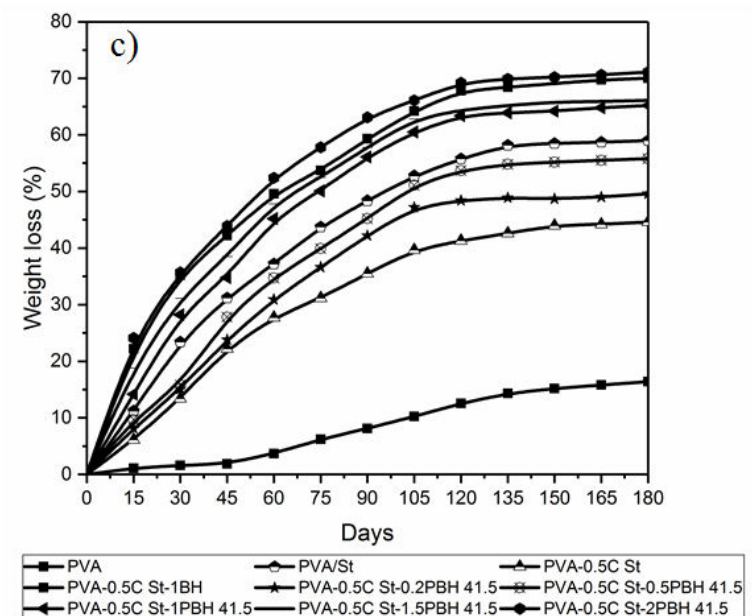
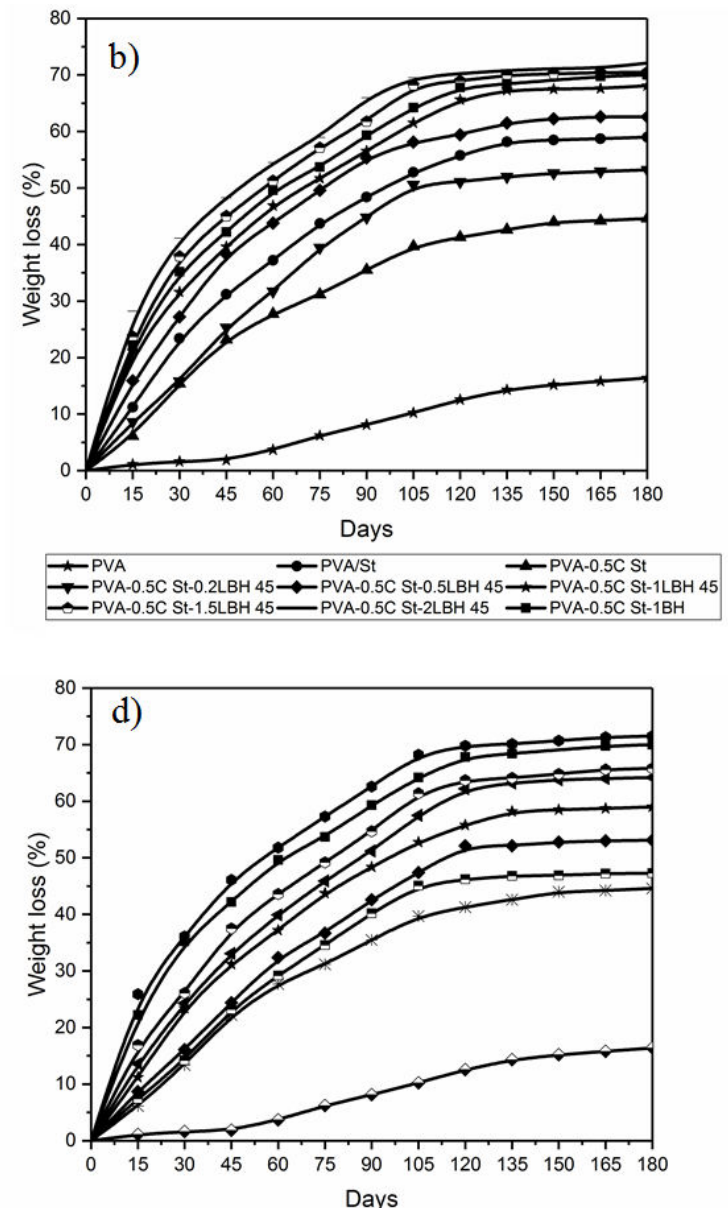

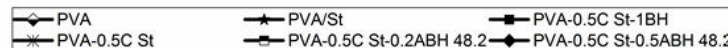

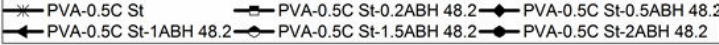

Fig. 2 Biodegradability of PVA/St based composite films reinforced with a) BH b) LBH 45, c) PBH 41.5, and d) 

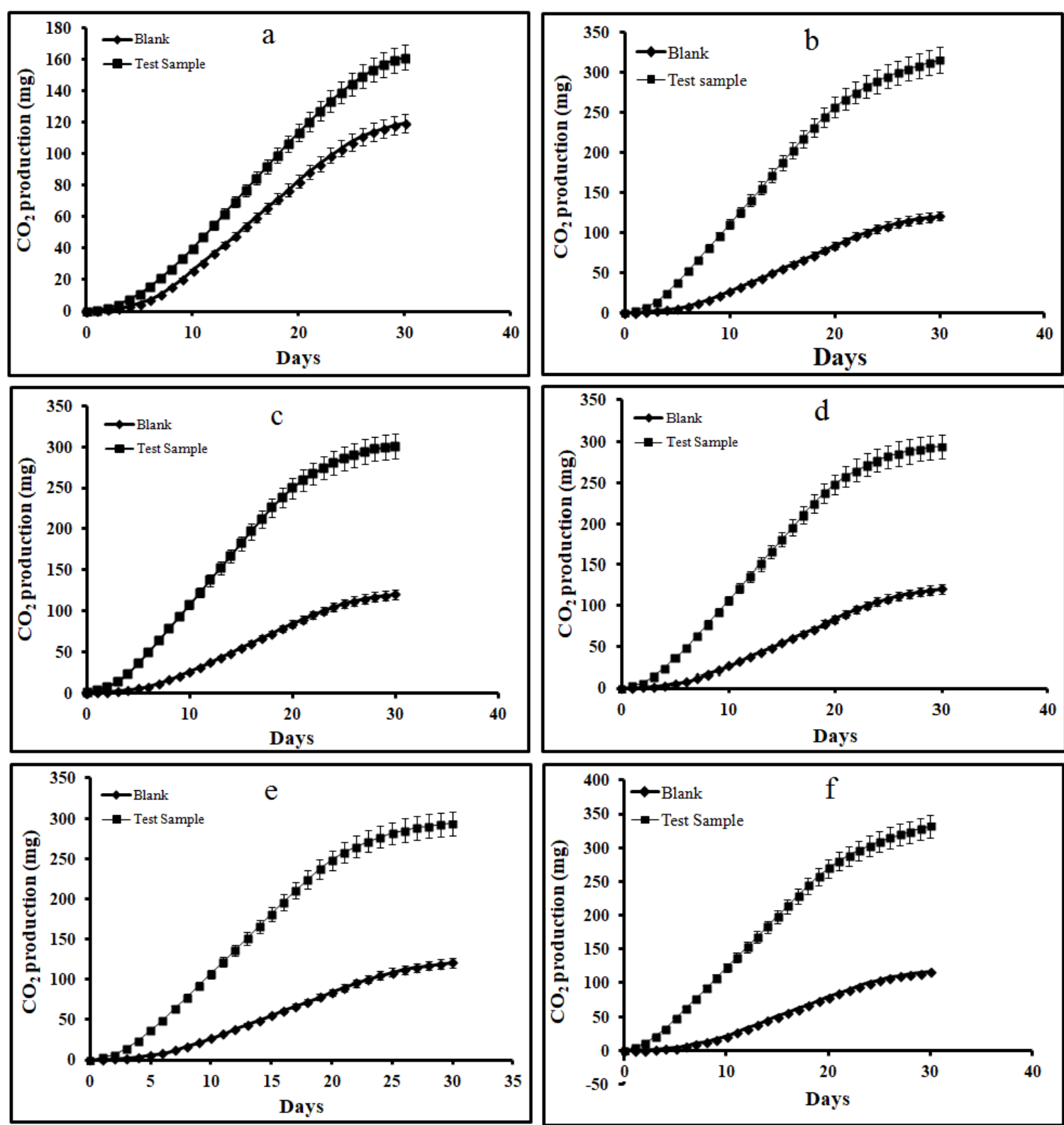

Fig. $3 \mathrm{CO}_{2}$ production during degradation of a) PVA b) PVA-0.5CSt-1BH c) PVA-0.5CSt-1LBH 45 d) PVA-

0.5CSt-1PBH 41.5 e) PVA-0.5CSt-1ABH 48.2 and f) aniline in aqueous aerobic medium. 

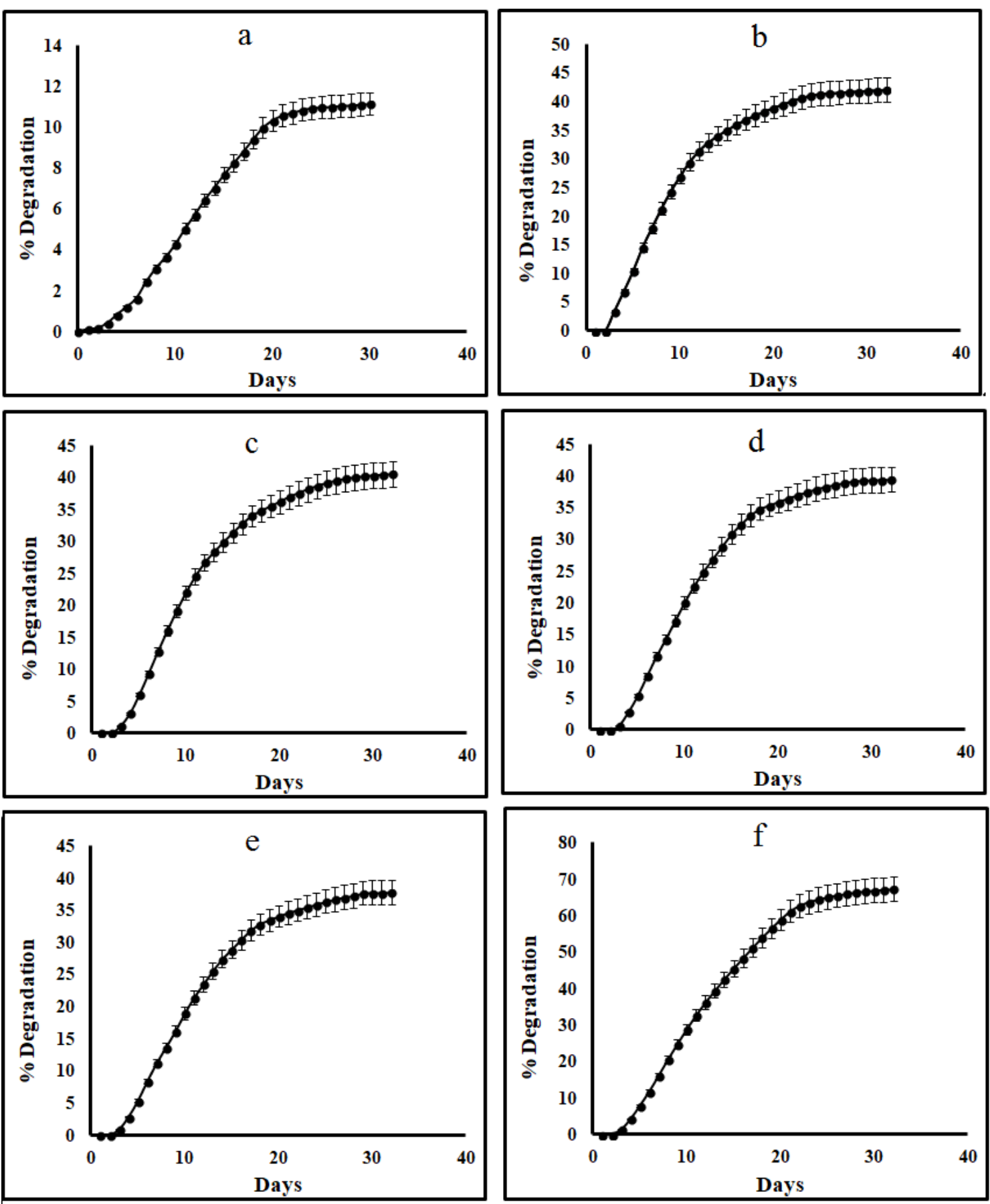

Fig. $4 \%$ Degradation of a) PVA b) PVA-0.5CSt-1BH c) PVA-0.5CSt-1LBH 45 d) PVA-0.5CSt-1PBH 41.5 e) 

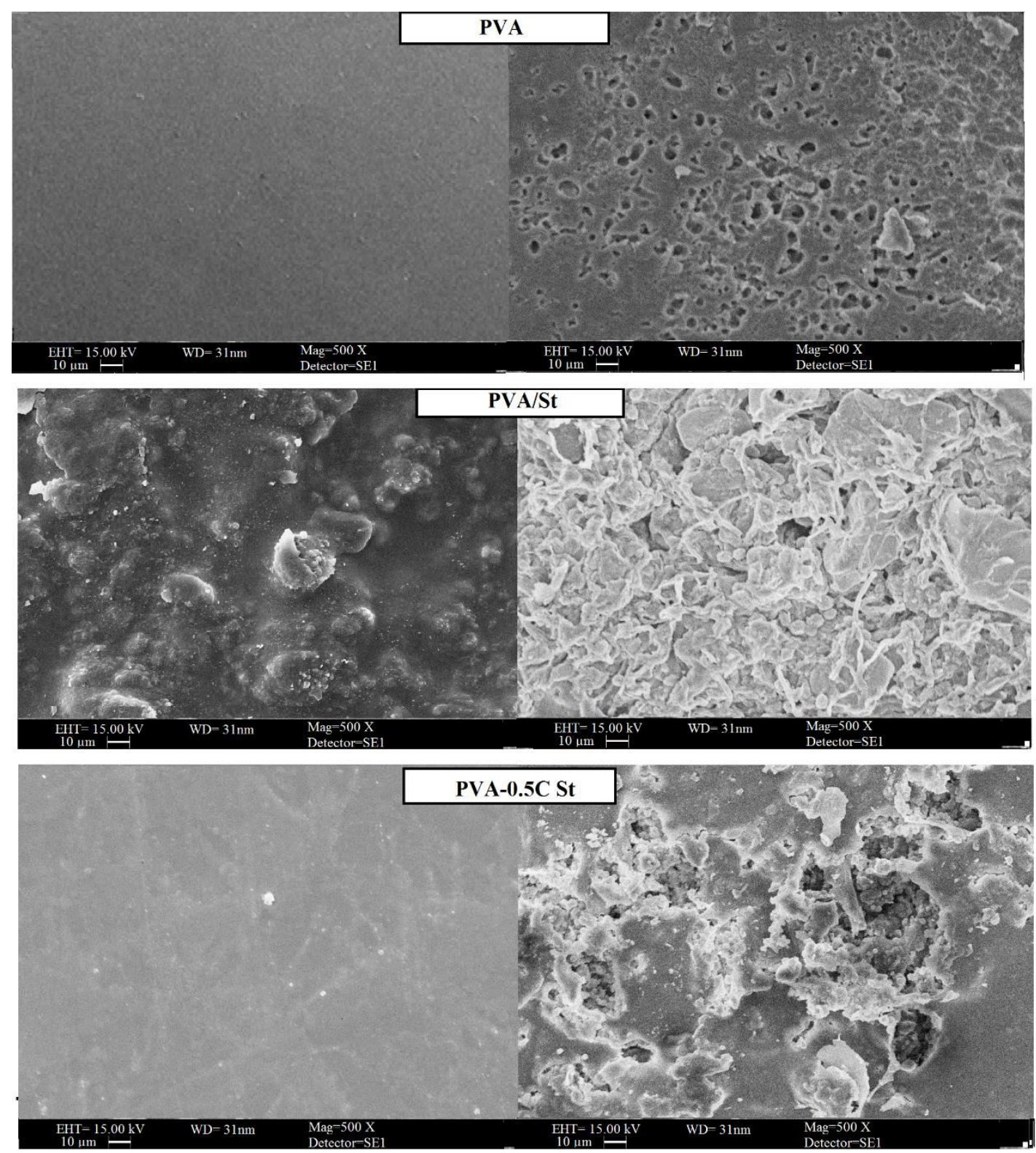

387 Fig. 5 SEM images of the PVA, PVA/St and crosslinked film (PVA-0.5C St) before and after 180 days of soil 

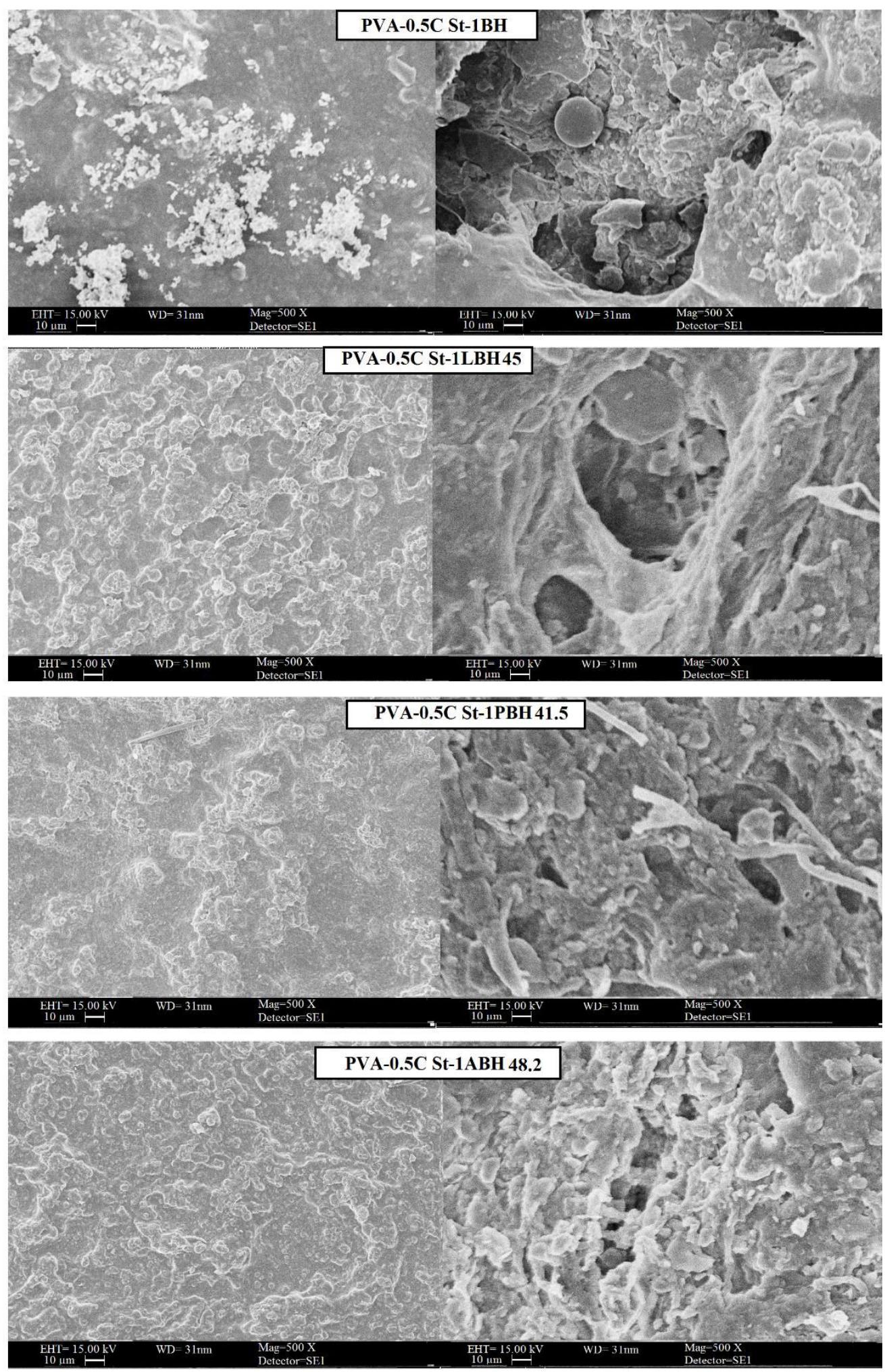

Fig. 6 SEM images of the composite films before and after 180 days of soil burial degradation test. 

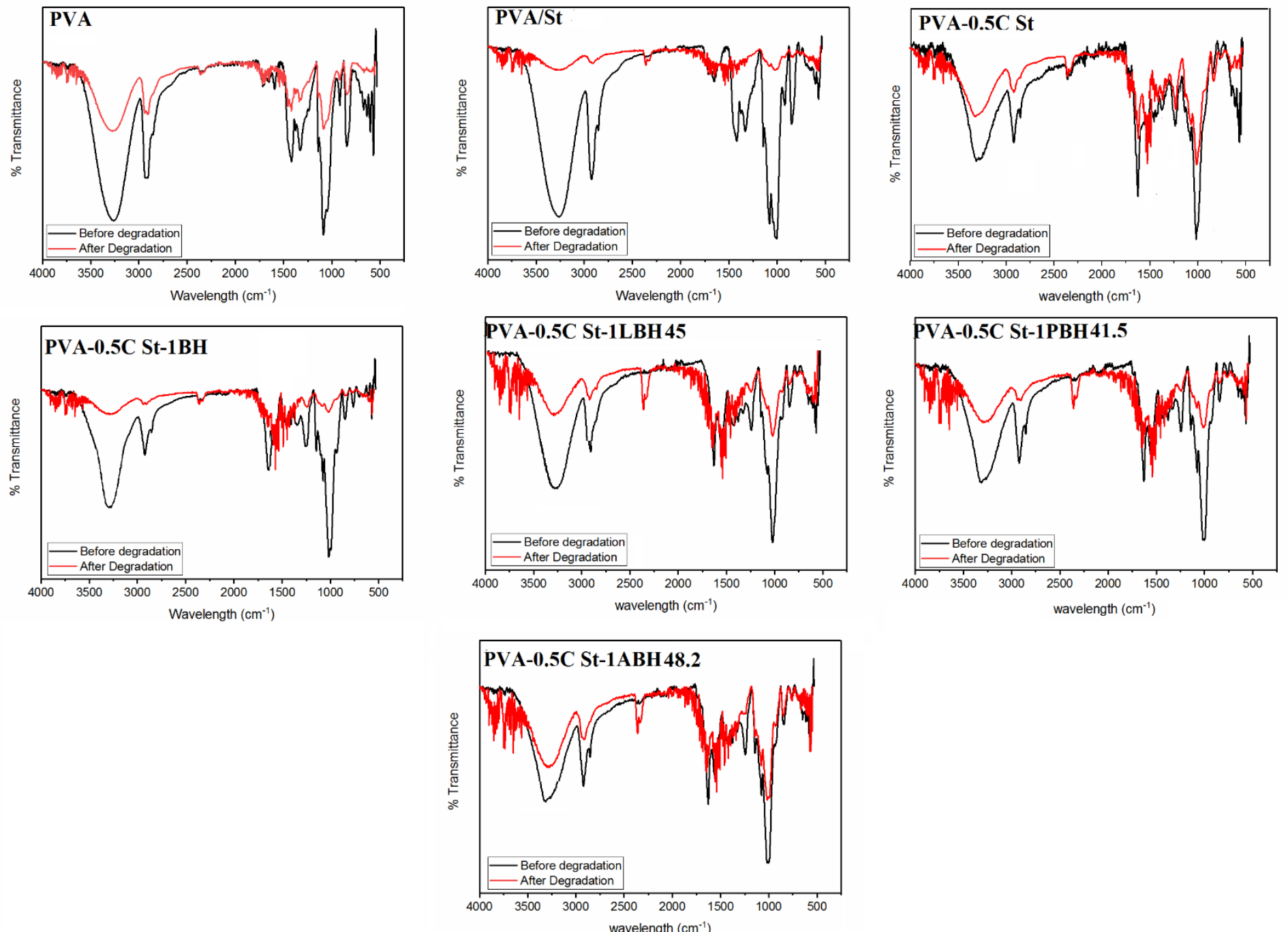

Table 1 Composition of various blend and composite films.

\begin{tabular}{|c|c|c|c|c|}
\hline Films & $\begin{array}{c}\text { PVA/starch } \\
\text { (w/w) }\end{array}$ & $\begin{array}{l}\text { Urea/ } \\
\text { starch } \\
(\mathrm{w} / \mathrm{w})\end{array}$ & $\begin{array}{c}\mathrm{BH} \\
(\% \mathrm{wt})\end{array}$ & $\begin{array}{l}\text { Grafted BH } \\
\quad(\% \text { wt })\end{array}$ \\
\hline PVA & $1 / 0$ & - & - & - \\
\hline $\mathrm{PVA} / \mathrm{St}$ & $1 / 1$ & - & - & - \\
\hline PVA/St-0.5C St & $1 / 1$ & 0.5 & - & - \\
\hline PVA/St-0.5C St-0.2BH & $1 / 1$ & 0.5 & 0.2 & - \\
\hline PVA/St-0.5C St-0.5BH & $1 / 1$ & 0.5 & 0.5 & - \\
\hline PVA/St-0.5C St-1BH & $1 / 1$ & 0.5 & 1 & - \\
\hline PVA/St-0.5C St-1.5BH & $1 / 1$ & 0.5 & 1.5 & - \\
\hline PVA/St-0.5C St-2BH & $1 / 1$ & 0.5 & 2 & - \\
\hline PVA/St-0.5C St-0.2LBH 45 & $1 / 1$ & 0.5 & - & 0.2 \\
\hline PVA/St-0.5C St-0.5LBH 45 & $1 / 1$ & 0.5 & - & 0.5 \\
\hline PVA/St-0.5C St-1LBH 45 & $1 / 1$ & 0.5 & - & 1 \\
\hline PVA/St-0.5C St-1.5LBH 45 & $1 / 1$ & 0.5 & - & 1.5 \\
\hline PVA/St-0.5C St-2LBH 45 & $1 / 1$ & 0.5 & - & 2 \\
\hline PVA/St-0.5C St-0.2PBH 41.5 & $1 / 1$ & 0.5 & - & 0.2 \\
\hline PVA/St-0.5C St-0.5PBH 41.5 & $1 / 1$ & 0.5 & - & 0.5 \\
\hline PVA/St-0.5C St-1PBH 41.5 & $1 / 1$ & 0.5 & - & 1 \\
\hline PVA/St-0.5C St-1.5PBH 41.5 & $1 / 1$ & 0.5 & - & 1.5 \\
\hline PVA/St-0.5C St-2PBH 41.5 & $1 / 1$ & 0.5 & - & 2 \\
\hline PVA/St-0.5C St-0.2ABH 48.2 & $1 / 1$ & 0.5 & - & 0.2 \\
\hline PVA/St-0.5C St-0.5ABH 48.2 & $1 / 1$ & 0.5 & - & 0.5 \\
\hline PVA/St-0.5C St-1ABH 48.2 & $1 / 1$ & 0.5 & - & 1 \\
\hline PVA/St-0.5C St-1.5ABH 48.2 & $1 / 1$ & 0.5 & - & 1.5 \\
\hline PVA/St-0.5C St-2ABH 48.2 & $1 / 1$ & 0.5 & - & 2 \\
\hline
\end{tabular}

2 


\section{Graphical Abstract}

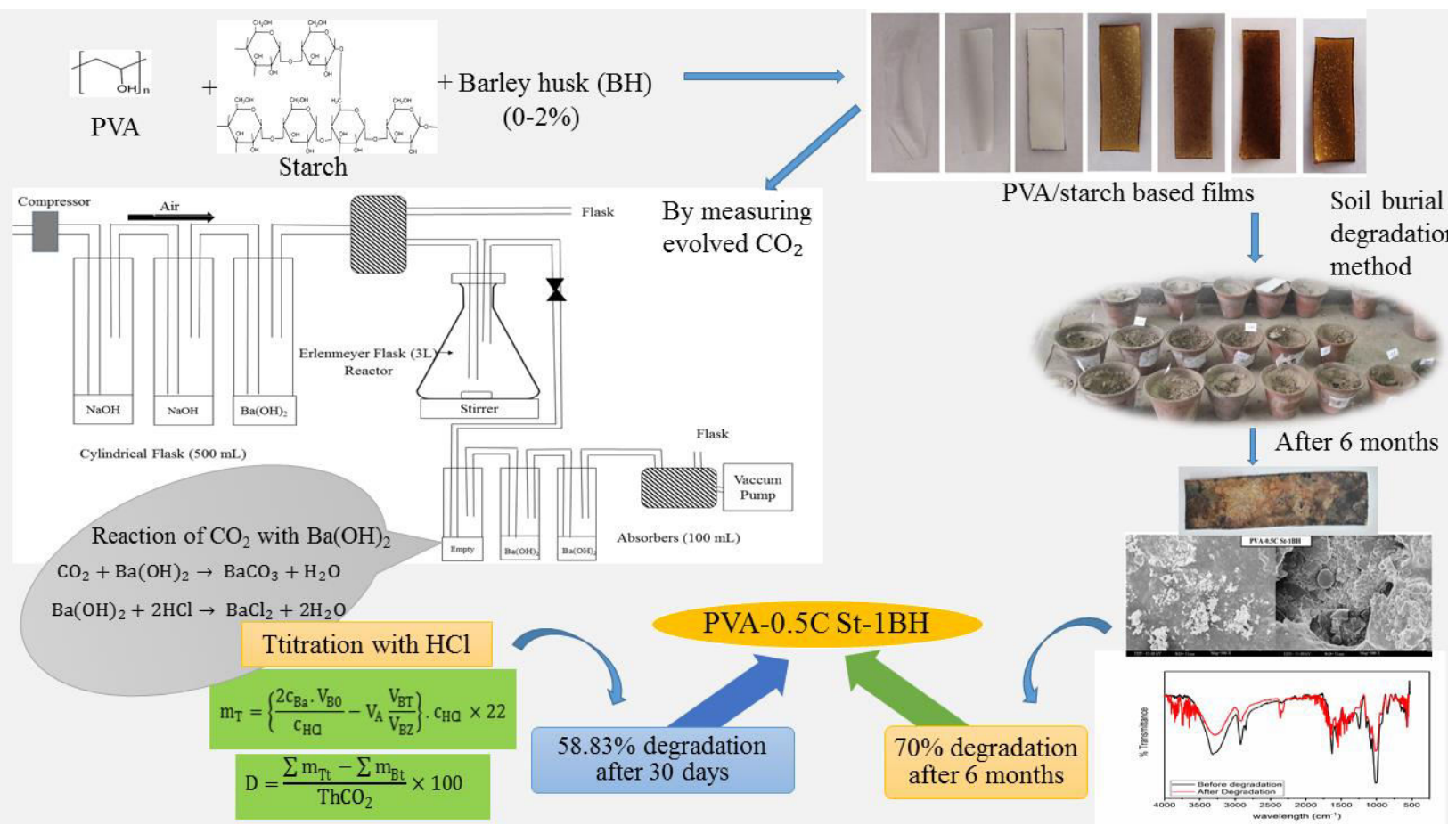

